\title{
Klasifikasi Kelulusan Mahasiswa Menggunakan Algoritma Learning Vector Quantization
}

\author{
Dwi Kartini ${ }^{1}$, Radityo Adi Nugroho ${ }^{2}$, Mohammad Reza Faisal $^{3}$ \\ 1,2,3 FMIPA, Universitas Lambung Mangkurat \\ Email : ${ }^{1}$ dwikartini@unlam.ac.id, ${ }^{2}$ reza.faisal@gmail.com, ${ }^{3}$ radityo.adi@gmail.com
}

\begin{abstract}
Abstrak
Program studi Ilmu Komputer FMIPA ULM meluluskan puluhan mahasiswa S1 setiap tahun. Salah satu kriteria penilaian pada akreditasi program studi adalah penilaian terhadap lama studi mahasiswa yang lulus tepat waktu. Pada penelitian ini akan dilakukan klasifikasi kelulusan berdasarkan status lama studi mahasiswa $\leq 4,5$ tahun = tepat waktu dan lama studi $>4,5$ tahun = tidak tepat waktu. Klasifikasi kelulusan mahasiswa berdasarkan IP semester I, Semester II, Semester III dan Semester IV yang telah lulus. Jika suatu sistem dapat melakukan klasifikasi kelulusan mahasiswa sebagai prediksi lama studi mahasiswa, diharapkan akan menjadi rekomendasi bagi dosen Penasehat Akademik memberikan nasehat kepada mahasiswa yang terdeteksi kemungkinan lulus tidak tepat waktu sehingga tindakan pencegahan Drop Out (DO) dapat diambil lebih awal. Hasil akurasi yang sesuai dengan data uji sebesar 70\% dengan menggunakan $\alpha=0.5$, decrement alfa 0.35 dan maxepoch $=500$.
\end{abstract}

Kata Kunci : kalsifikasi, kelulusan, Learning Vector Quantization, jaringan saraf tiruan.

\begin{abstract}
Computer Science Study Program FMIPA ULM graduates dozens of undergraduate students every year. One of the assessment criteria for the accreditation of the study program is the assessment of the duration of the study of students who graduated on time. In this research will be done classification of graduation based on the status of student study year = timely and study length 4.5 years $=$ not on time. Classification of students passing graduation based on IP semester I, Semester II, Semester III and Semester IV that have passed. If a system can classify students' graduation as a predictor of the duration of a student study, it is expected to be a recommendation for the Academic Advisors lecturers giving advice to students who are detected in the timely graduation possibilities so that Drop Out (DO) prevention measures may be taken earlier. Accuracy results are in accordance with the test data of $70 \%$ by using $\alpha=0.5$, decrement alfa 0.35 and maxepoch $=500$.
\end{abstract}

Keywords: classification, graduation, Learning Vector Quantization, artificial neural network

\section{PENDAHULUAN}

\subsection{Latar Belakang}

Salah satu kriteria penilaian pada akreditasi program studi adalah penilaian terhadap lama studi mahasiswa yang lulus tepat waktu. Lama studi mahasiswa dapat dipengaruhi oleh banyak faktor. Pada penelitian ini, akan dilakukan klasifikasi kelulusan mahasiswa berdasarkan IP semester I, Semester II, Semester III dan Semester IV mahasiswa yang telah lulus. Apabila suatu sistem dapat memperkirakan atau memprediksi dini seorang mahasiswa lulus tepat waktu ataupun tidak tepat waktu sehingga dapat menjadi rekomendasi perguruan tinggi dalam menentukan kebijakan terkait pencegahan dini kasus DropOut (DO). Penasehat akademik dapat merujuk ke hasil prediksi ketika memberikan nasehat kepada mahasiswa yang terdeteksi kemungkinan terlambat lulus sehingga tindakan pencegahan dapat diambil lebih awal (L.S. Affendey,2010). Di samping itu, seorang instruktur atau para pengajar dapat lebih meningkatkan mengajar dan pendekatan pembelajaran, serta intervensi merencanakan dan layanan dukungan bagi mahasiswa.

Beberapa Penelitian terdahulu mengenai prediksi menggunakan jaringan syaraf tiruan dilakuakan dengan judul Early Model Of Student's Graduation Prediction Based Neural Network yang menggunakan nilai Indek Prestasi Semester 1 sampai IPS 3 sebagai variabel input. Tahun 2015 dengan judul Prediksi Kelulusan Mahasiswa menggunakan Metode Neural 
Network dan Particle Swarm Optimization. Penelitian yang dilakukan tentang terjangkitnya penyakit jantung juga menggunakan metode LVQ. Penelitian ini menggunakan 10 variabel input dan target berupa kategori tidak terjangkit penyakit jantung dan terjangkit penyakit jantung, berturut-turut dengan nilai 1 dan 2 . Tingkat keberhasilan jaringan LVQ untuk dapat mengenali pola dengan benar adalah sebesar $66.79 \%$.Tingkat akurasi hasil pengklasifikasian tergantung pada jumlah data yang digunakan dalam proses pembelajaran, semakin banyak data yang dilatih tingkat akurasi pada pengujiannya akan semakin baik karena pola pelatihan yang tersimpan akan semakin banyak.

Jaringan Syaraf Tiruan terawasi (supervised) seperti Learning Vector Quantization (LVQ) adalah suatu metode klasifikasi pola yang masing-masing unit output mewakili kategori atau kelompok tertentu, pemprosesan yang terjadi pada setiap neuron adalah mencari jarak terdekat antara satu vektor masukan kebobot yang bersangkutan. Penerapan metode LVQ digunakan di dalam mencari bobot yang sesuai, untuk mengelompokkan vektorvektor input ke dalam kelas-kelas yang telah diinisialisasikan pada saat pembentukan jaringan LVQ. Jaringan syaraf tiruan LVQ diharapkan dapat digunakan dalam mengklasifikasikan kelulusan mahasiswa berdasarkan IP semester I, Semester II, Semester III dan Semester IV mahasiswa yang telah lulus dan dijadikan sebagai pengetahuan dalam menentukan prediksi dini kelulusan mahasiswa.

\subsection{Landasan Teori}

\subsubsection{Jaringan Syaraf Tiruan}

Jaringan syaraf tiruan merupakan salah satu sistem pemrosesan informasi yang didesain meniru cara kerja otak manusia dalam menyelesaikan suatu masalah dengan melakukan proses belajar melalui perubahan bobot dan sinapsisnya. Jaringan syaraf tiruan mampu mengenali kegiatan dengan berbasis pada data masa lalu. Data masa lalu akan dipelajari oleh jaringan syaraf tiruan sehingga mempunyai kemampuan untuk memberi keputusan terhadap data yang belum pernah dipelajari (Arief Hermawan,2006).

Menurut J.J Siang (2005), jaringan syaraf tiruan dibentuk sebagai generalisasi model matematika dari jaringan syaraf biologi dengan asumsi:

a. Pemrosesan informasi terjadi pada banyak elemen sederhana (neurons). b. Sinyal dikirimkan diantara neuron-neuron melalui penghubung-penghubung.

c. Penghubung antar neuron memiliki bobot yang akan memperkuat atau memperlemah sinyal.

d. Untuk menentukan output, setiap neuron menggunakan fungsi aktivasi (biasanya bukan fungsi linier) yang dikenakan pada jumlahan input yang diterima. Besarnya output ini selanjutnya dibandingkan dengan suatu batas ambang (threshold).

\subsubsection{Arsitektur Jaringan LVQ}

Learning vector quantization merupakan suatu metode untuk melakukan pembelajaran pada lapisan kompetitif yang terawasi. Suatu lapisan kompetitif akan secara otomatis belajar untuk mengelompokkan vektor-vektor masukan. Kelas-kelas yang didapatkan sebagai hasil dari lapisan kompetitif ini hanya tergantung pada jarak antara vektor-vektor masukan. Jika dua vektor masukan mendekati sama, maka lapisan kompetitif akan meletakkan kedua vektor masukan tersebut ke dalam kelas yang sama. Untuk setiap unit keluaran akan mewakili sebuah kelas. Learning vector quantization termasuk jaringan syaraf dengan tipe arsitektur jaringan layar tunggal (Single Layer Network) yang terdiri atas lapisan masukan dan lapisan keluaran (Kusumadewi, 2003).

Arsitektur LVQ terdiri dari lapisan input (input layer), lapisan kompetitif (terjadi kompetisi pada input untuk masuk ke dalam suatu kelas berdasarkan kedekatan jaraknya) dan lapisan output (output layer). Lapisan input dihubungkan dengan lapisan kompetitif oleh bobot. Dalam lapisan kompetitif, proses pembelajaran dilakukan secara terawasi (Ranadhi, 2006). Input akan bersaing untuk dapat masuk ke dalam suatu kelas.

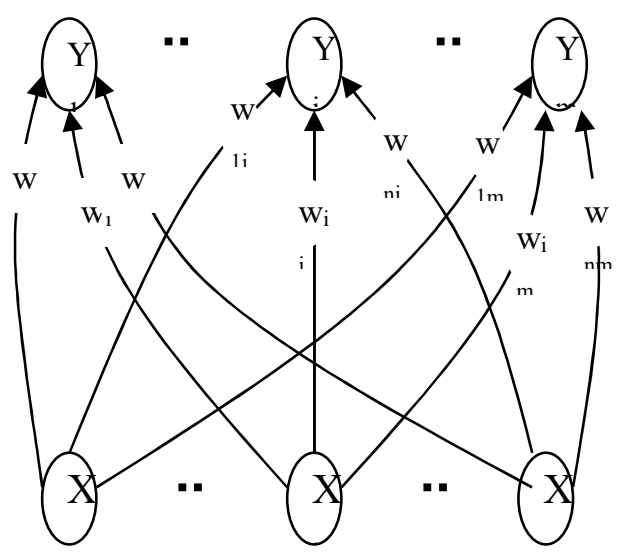

Gambar 1. Jaringan Syaraf Learning Vector Quantization (Fausett 1994) 
Algoritma LVQ bertujuan akhir mencari nilai bobot yang sesuai untuk mengelompokkan vektor-vektor kedalam kelas tujuan yang telah di inisialisasi pada saat pembentukan jaringan LVQ. Sedangkan algoritma pengujiannya adalah menghitung nilai output (kelas vektor) yang terdekat dengan vektor input, atau dapat disamakan dengan proses pengklasifikasian (pengelompokan).

Keterangan yang kita gunakan adalah sebagai berikut:

$\mathrm{X} \quad$ : vektor pelatihan (input) $\left(\mathrm{x}_{1}, \ldots, \mathrm{x}_{\mathrm{i}}, . ., \mathrm{x}_{\mathrm{n}}\right)$

$\mathrm{T} \quad$ : kategori yang tepat atau kelas untuk vektor pelatihan

$\mathrm{W}_{\mathrm{j}} \quad$ : bobot vektor untuk unit output ke-j $\left(\mathrm{w}_{1 \mathrm{j}}, \ldots \ldots . ., \mathrm{w}_{\mathrm{ij}}, \ldots \ldots . ., \mathrm{w}_{\mathrm{nj}}\right)$

$\mathrm{C}_{\mathrm{j}} \quad$ : kategori atau kelas yang ditampilkan oleh unit output ke-j

$\left\|\mathrm{x}-\mathrm{w}_{\mathrm{j}}\right\|$ : jarak Euclidean antara vektor input dan bobot vektor untuk layer output ke-j.

Berikut ini adalah algoritma pembelajaran LVQ: langkah 0: inisialisasi vektor referensi ; inisialisasi rating pembelajaran $\alpha(0)$

langkah 1: ketika kondisi berhenti adalah false, lakukan langkah 2 sampai 6

langkah 2: untuk setiap input pelatihan vektor $\mathrm{x}$ lakukan langkah $3-4$

langkah 3 : temukan $\mathrm{j}$ hingga $\left\|\mathrm{x}-\mathrm{w}_{\mathrm{j}}\right\|$ minimum langkah 4 : perbaharui $\mathrm{w}_{\mathrm{j}}$ sebagai berikut :

jika $\mathrm{T}=\mathrm{C}_{\mathrm{j}}$, maka

$\mathrm{W}_{\mathrm{j}}($ baru $)=\mathrm{W}_{\mathrm{j}}($ lama $)+\alpha\left[\mathrm{x}-\mathrm{W}_{\mathrm{j}}(\right.$ lama $\left.)\right]$;

jika $\mathrm{T} \neq \mathrm{C}_{\mathrm{j}}$, maka

$\mathrm{W}_{\mathrm{j}}($ baru $)=\mathrm{W}_{\mathrm{j}}($ lama $)-\alpha\left[\mathrm{x}-\mathrm{W}_{\mathrm{j}}(\right.$ lama $\left.)\right]$;

langkah 5 : kurang rating pelatihan

langkah 6: tes kondisi berhenti: yaitu kondisi yang mungkin menetapkan sebuah jumlah tetap dari iterasi atau rating pembelajaran mencapai nilai kecil yang cukup.

Setelah proses pembelajaran Learning Vector Quantization (LVQ) maka langkah selanjutnya adalah proses pengambilan hasil output Learning Vector Quantization (LVQ). Pengambilan hasil dilakukan hanya pada proses Testing (pengujian). Pada dasarnya, tahapan ini hanya memasukkan input bobot akhir kemudian mencari jarak terdekat dengan perhitungan Euclidian (jarak terdekat) (Fausett, 1994).

\section{METODE PENELITIAN}

\subsection{Prosedur Penelitian}

Penelitian ini pertama diawali dengan tahap pencarian literatur, identifikasi dan pengumpulan data, tahap persiapan dan pemilihan data dan proses klasifikasi untuk klasifikasi kelulusan mahasiswa menggunakan algoritma Learning Vector Quantization :

1. Pencarian Literatur

Tahap ini adalah mencari literatur dari buku-buku maupun jurnal penelitian terdahulu tentang klasifikasi kelulusan mahasiswa, jaringan syaraf tiruan algoritma Learning Vector Quantization.

2. Identifikasi dan Pengumpulan Data

Pada tahap ini dilakukan identifikasi terhadap pengumpulan data yang sesuai dengan penelitian. Data yang digunakan adalah data akademik mahasiswa didapatkan dari bidang akademik FMIPA ULM.

3. Persiapan dan Pemilihan Data

Melakukan persiapan terhadap data yang telah didapat seperti melihat struktur tabel yang ada pada database. Pemilihan data dilakukan karena tidak semua tabel serta field yang ada dalam database akan digunakan. Data yang akan digunakan dalam penelitian ini ialah berupa IP Semester I hingga semester IV mahasiswa angkatan 2006-2012 yang memiliki nilai matakuliah skripsi seperti pada tabel 1 . Lama studi mahasiswa diklasifikasikan menjadi dua kategori yaitu Jika status lama studi mahasiswa $\mathbf{5} \mathbf{4 , 5}$ tahun = lulus tepat waktu dan lama studi $>4,5$ tahun $=$ lulus tidak tepat waktu yang terdapat pada tabel 2.

Tabel 1. Lama Studi mahasiswa berdasarakan IP

\begin{tabular}{|l|r|r|r|r|r|}
\hline Angkatan & \multicolumn{1}{c|}{ ips1 } & \multicolumn{1}{c|}{ ips2 } & \multicolumn{1}{c|}{ ips3 } & \multicolumn{1}{c|}{ ips4 } & Ls(tahun) \\
\hline 2007 & 2.21 & 2.21 & 2.67 & 3.29 & 6 \\
\hline 2007 & 2.36 & 2 & 2.5 & 2.64 & 5.9 \\
\hline 2007 & 2.86 & 2.23 & 3.19 & 3.5 & 5.5 \\
\hline 2007 & 2.93 & 2.52 & 3.24 & 3.62 & 4.5 \\
\hline$\ldots \ldots$ & $\ldots \ldots$ & $\ldots \ldots$ & $\ldots \ldots$ & $\ldots \ldots$ & $\ldots \ldots$ \\
\hline$\ldots \ldots$ & $\ldots \ldots$ & $\ldots \ldots$ & $\ldots \ldots$ & $\ldots \ldots$ & $\ldots \ldots$ \\
\hline$\ldots \ldots$ & $\ldots \ldots$ & $\ldots \ldots$ & $\ldots \ldots$ & $\ldots \ldots$ & $\ldots \ldots$ \\
\hline 2012 & 3.18 & 2.55 & 3.38 & 3.29 & 4.8 \\
\hline 2012 & 2.73 & 2.06 & 3.3 & 3.02 & 4.8 \\
\hline
\end{tabular}


Tabel 1. Lama studi alumni

\begin{tabular}{|c|c|}
\hline lama Studi & kategori \\
\hline$\leq 4,5$ tahun & Tepat waktu \\
\hline$>4,5$ tahun & Tidak tepat waktu \\
\hline
\end{tabular}

\section{Implementasi Learning Vector} Quantization

Pada tahap ini data yang telah ditransformasi akan dibagi menjadi data pelatihan dan data pengujian yang akan diiplementasi model neural network Learning Vector Quantization menggunakan variabel ips1, ips2, ips3, ips4 dan lama studi data mahasiswa angkatan 2006 sampai 2012 yang telah lulus. Evaluasi akan dilakukan dengan mengamati hasil klasifikasi kelulusan mahasiswa. Algoritma proses pembelajaran pada metode LVQ disajikan pada gambar 2. Setelah dilakukan pelatihan, akan diperoleh bobot-bobot akhir (W). Bobot-bobot ini selanjutnya digunakan untuk melakukan simulasi atau pengujian. Algoritma proses pengujian pada metode LVQ disajikan pada Gambar 3 (Fausset, 1994).

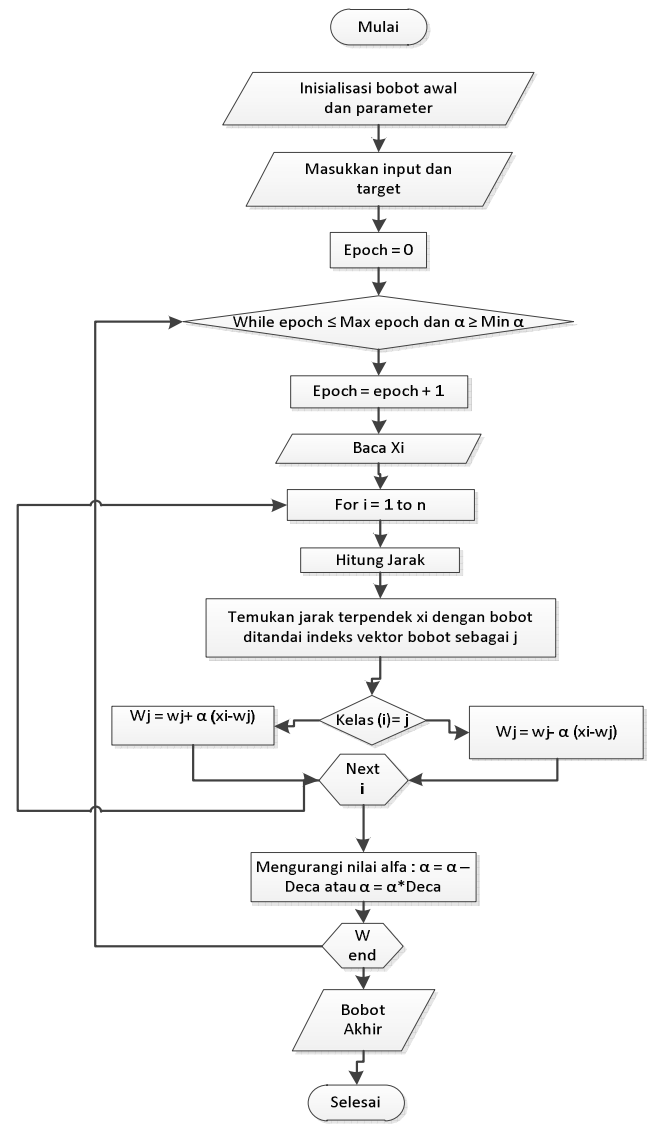

Gambar 2 Algoritma Proses Pembelajaran pada Metode Learning Vector Quantization (LVQ)

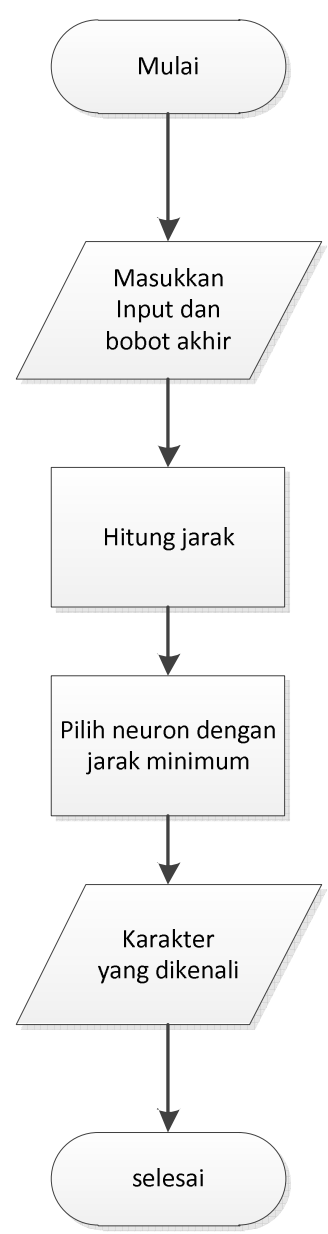

Gambar 3. Algoritma Proses Pengujian pada Metode Learning Vector Quantization (LVQ)

\section{HASIL DAN PEMBAHASAN}

Pada bagian ini dibahas klasifikasi kelulusan mahasiswa berdasarkan variabel input berupa IP semester I, Semester II, Semester III dan Semester IV dengan data lulusan sebanyak 237 dibagi menjadi 200 data pelatihan dan 37 data pengujian. Target/sasaran (Y) yang diinginkan juga harus dituliskan. Dalam hal ini targetnya berupa klasifikasi lulusan Tepat waktu dan tidak tepat waktu. Agar dapat dikenali oleh jaringan, kategori harus diubah ke dalam bentuk numerik, yaitu :

- Diberi nilai "1" jika lulus tepat waktu

- Diberi nilai "2" jika lulus tidak tepat waktu

Pada proses pelatihan data, peneliti memasukkan data latih yang akan digunakan sebagai bahan pembelajaran dan data parameterparameter LVQ yang dibutuhkan. Adapun parameter yang digunakan pada penelitian ini berupa bobot awal yang terdapat pada tabel 3 dengan menggunakan alfa (Learning rate), $\alpha=$ 0.5 , DecAlfa (Penurunan Learning rate), Dec $\alpha=$ 0.35 serta MaxEpoch (Maksimum epoch), MaxEpoch $=500$. 
Tabel 3. Bobot awal proses pembelajaran

\begin{tabular}{|r|r|r|r|r|}
\hline kelas & $\mathrm{W}_{\mathrm{i} 1}$ & $\mathrm{~W}_{\mathrm{i} 2}$ & $\mathrm{~W}_{\mathrm{i} 3}$ & $\mathrm{~W}_{\mathrm{i} 4}$ \\
\hline 1 & 2.94 & 2.55 & 3 & 3.41 \\
\hline 2 & 2.62 & 1.98 & 2.58 & 2.42 \\
\hline
\end{tabular}

Hasil atau output dari pelatihan data yang didapatkan berupa data bobot akhir optimal yang mewakili jarak dari tiap kelas output yang akan digunakan pada proses pengujian dengan menggunakan perhitungan jarak eucledian antara data uji terhadap data bobot optimal yang didapatkan dari proses pelatihan. Berdasarkan hasil klasifikasi pengujian data uji sebanyak 37 dataset menunjukkan bahwa terdapat 11 dataset yang tidak sesuai dengan target atau terjadi kesalahan dan 26 dataset yang masuk pada target/kelas yang sama. Percobaan pelatihan dan pengujian ini menghasilkan akurasi pengujian sebesar $70 \%$ yang terdapat pada tabel 4 .

Tabel 4. Hasil pengujian klasifikasi kelulusan mahasiswa

\begin{tabular}{|c|c|c|c|c|c|}
\hline data ke & kelas 1 & kelas 2 & target & output & hasil \\
\hline 1 & 0.669477 & 1.231097 & 1 & 1 & sesuai \\
\hline 2 & 1.03436 & 0.936536 & 2 & 2 & sesuai \\
\hline 3 & 1.119375 & 0.998599 & 1 & 2 & $\begin{array}{c}\text { tidak } \\
\text { sesuai }\end{array}$ \\
\hline 4 & 0.704699 & 1.033441 & 2 & 1 & $\begin{array}{c}\text { tidak } \\
\text { sesuai }\end{array}$ \\
\hline 5 & 0.710915 & 1.678213 & 2 & 1 & $\begin{array}{c}\text { tidak } \\
\text { sesuai }\end{array}$ \\
\hline 6 & 1.148172 & 1.318294 & 2 & 1 & $\begin{array}{c}\text { tidak } \\
\text { sesuai }\end{array}$ \\
\hline 7 & 0.593633 & 1.463352 & 1 & 1 & sesuai \\
\hline 8 & 2.042131 & 0.955563 & 2 & 2 & sesuai \\
\hline 9 & 1.907407 & 0.743102 & 2 & 2 & sesuai \\
\hline 10 & 2.37154 & 1.292362 & 2 & 2 & sesuai \\
\hline 11 & 1.500067 & 0.567274 & 2 & 2 & sesuai \\
\hline 12 & 2.243457 & 1.136442 & 2 & 2 & sesuai \\
\hline 13 & 2.703368 & 1.607794 & 2 & 2 & sesuai \\
\hline 14 & 1.725167 & 0.536843 & 2 & 2 & sesuai \\
\hline 15 & 1.718459 & 0.659773 & 2 & 2 & sesuai \\
\hline 16 & 0.911043 & 0.628808 & 2 & 2 & sesuai \\
\hline 17 & 1.740948 & 0.758222 & 2 & 2 & sesuai \\
\hline 18 & 1.538376 & 0.466905 & 1 & 2 & $\begin{array}{c}\text { tidak } \\
\text { sesuai }\end{array}$ \\
\hline 19 & 2.360445 & 1.299192 & 1 & 2 & $\begin{array}{c}\text { tidak } \\
\text { sesuai }\end{array}$ \\
\hline 20 & 2.425551 & 1.433422 & 1 & 2 & $\begin{array}{c}\text { tidak } \\
\text { sesuai }\end{array}$ \\
\hline 21 & 1.936801 & 0.846286 & 1 & 2 & $\begin{array}{c}\text { tidak } \\
\text { sesuai }\end{array}$ \\
\hline 22 & 1.03131 & 0.234521 & 2 & 2 & sesuai \\
\hline 23 & 1.824445 & 0.823286 & 2 & 2 & sesuai \\
\hline
\end{tabular}

\begin{tabular}{|c|c|c|c|c|c|}
24 & 2.153277 & 1.150391 & 2 & 2 & sesuai \\
\hline 25 & 1.147127 & 0.494874 & 2 & 2 & sesuai \\
\hline 26 & 2.430823 & 1.433143 & 1 & 2 & $\begin{array}{c}\text { tidak } \\
\text { sesuai }\end{array}$ \\
\hline 27 & 1.855505 & 0.804674 & 2 & 2 & sesuai \\
\hline 28 & 2.543777 & 1.439375 & 1 & 2 & $\begin{array}{c}\text { tidak } \\
\text { sesuai }\end{array}$ \\
\hline 29 & 1.607576 & 0.603407 & 2 & 2 & sesuai \\
\hline 30 & 0.955772 & 0.331512 & 2 & 2 & sesuai \\
\hline 31 & 1.592577 & 0.684178 & 2 & 2 & sesuai \\
\hline 32 & 1.347776 & 0.959531 & 2 & 2 & sesuai \\
\hline 33 & 1.17703 & 0.466905 & 2 & 2 & sesuai \\
\hline 34 & 1.495326 & 0.62498 & 1 & 2 & $\begin{array}{c}\text { tidak } \\
\text { sesuai }\end{array}$ \\
\hline 35 & 1.234747 & 0.437721 & 2 & 2 & sesuai \\
\hline 36 & 1.426674 & 0.465188 & 2 & 2 & sesuai \\
\hline 37 & 0.947048 & 0.725465 & 2 & 2 & sesuai \\
\hline
\end{tabular}

\section{KESIMPULAN}

Berdasarkan hasil pengujian yang telah dilakukan untuk klasifikasi kelulusan mahasiswa menggunakan jaringan saraf tiruan Learning Vector Quantization ini, dapat menjadi rekomendasi bagi Penasehat Akademik untuk memprediksi dini kelulusan mahasiswa sehingga tindakan pencegahan Drop Out (DO) dapat diambil lebih awal. Hasil Penelitian ini menunjukan tingkat akurasi $70 \%$ untuk data pengujian yang dikenal jaringan sesuai target dan $30 \%$ tidak sesuai dengan target. Hal ini bisa disebabkan karena banyak faktor lain yang mempengaruhi proses belajar mahasiswa dalam mengikuti perkuliahan baik faktor internal, maupun external dalam menyelesaikan studinya.

\section{REFERENSI}

Fausset, L.V., Fundamentals of Neural Network: Arsitecture, Algorithm, and Aplication, Prentice Hall, New Jersey, 1994.

Hermawan, Arief. 2006. Jaringan Saraf Tiruan Teori da Aplikasi. Yogyakarta : Andi Offset.

Hidayati, N. \& Warsito, B. 2010. Prediksi Terjangkitnya Penyakit Jantung Dengan Metode Learning Vector Quantization. Media Statistika, 3 (1). pp. 21-30. ISSN 1979-3693.

Kusumawati, Dewi, dkk. 2009. Prediksi Kelulusan Mahasiswa Menggunakan Metode Neural Network dan Particle Swarm Optimization. Nasional Teknologi Informasi dan Multimedia 2015. 
Jurnal Positif, Volume 3, No.2, 2017 : 93 - 98

L.S. Affendey, I.H.M. Paris, N. Mustapha, Md. Nasir Sulaiman, and Z. Muda, "L.S Affendey Ranking of Influencing Factors in Predicting Students Academic Performance," April 2010

Rahmani, Budi dan Hugo Aprilianto. 2014. Early Model of Student's Graduation Prediction. Journal Telkomnika. Vol.12 No. 2: 465474.

Siang, JJ. 2005. Jaringan syaraf Tiruan dan Pemrograman Menggunakan Matlab. Yogyakarta: Andi Offset

Ranadhi, D., Indarto, W., dan Hidayat, T., Implementasi Learning Vector Quantization (LVQ) untuk Pengenal Pola Sidik Jari pada Sistem Informasi Narapidana LP Wirogunan, Media Informatika, 2006, Vol. 4, No. 1: 51-65. 